\title{
HISTÓRIA \& DIREITO COLONIAL: UM DEBATE AUDACIOSO
}

\author{
MÁRCIA MARIA MENENDES MOTTA ${ }^{1}$
}

RESUMO: O texto a seguir reconstitui as principais questões acerca da querela que envolveu dois grandes modernistas nos anos 2000: o português Antônio Manuel Hespanha e a brasileira Laura de Mello e Souza. O fértil debate entre os dois estava assentado nas discordantes posições sobre o chamado direito colonial na América Portuguesa. Como desdobramento, havia também a pertinência ou não do emprego do conceito de Antigo Regime para a colônia. A partir do diálogo sobre a produção dos dois emblemas da produção historiográfica luso-brasileira, o artigo aponta algumas reflexões sobre o direito proveniente dos exemplares estudos do inglês $E$. P. Thompon e do sociólogo francês $P$. Bourdieu.

Palavras-chave: Historiografia luso-brasileira. Direito colonial. Antigo Regime.

\section{History and colonial law: an audacious debate}

\begin{abstract}
This article reconstitutes the main questions about the quarrel involving two great colonialist in the 2000s: Portuguese Antônio Manuel Hespanha anda Brazilian Laura de Mello e Souza. The fertile debate between the two was based on discordant positions on the so-called colonial law in Portuguese America. As a development, there was also the pertinence or not of the use of the concept of Ancient Regime for the colony. From the dialogue on the production of the two emblems of Luso-Brazilian historiographical production, the article points out some reflections on the law based on the exemplary studies of English E. P. Thompson and the French sociologist P. Bourdieu.
\end{abstract}

Keywords: Luso-Brazilian historiographical. Colonial law. Ancient Regime.

\section{Introdução}

Em fins da década de 2000, dois grandes investigadores luso-brasileiros expressaram suas posições discordantes acerca do direito na colônia: Antônio Manuel Hespanha e Laura de Mello e Souza. Ao que tudo indica, a querela se iniciara em um embate produzido por alguns dos renomados discípulos de Hespanha, em um evento ocorrido em Parati, Rio de Janeiro.

O presente artigo reconstrói alguns percursos das discordâncias entre os dois, a partir das leituras de suas obras e aponta algumas questões que envolvem a relação entre História e Direito, com base nas reflexões de E. P. Thompson e P. Bourdieu. Como desdobramento, considera que uma maior aproximação com os escritos desses autores permite-nos esquadrinhar melhor a complexa relação entre o conhecimento

\footnotetext{
${ }^{1}$ Doutora em História Social do Trabalho (UNICAMP). Professora do Departamento de História da UFF. E-mail: menendesmotta9@gmail.com
} 
histórico e as possibilidades abertas pelo Direito exercido nas colônias.

\section{Hespanha, Mello e Souza e a querela}

O historiador do Direito, Antônio Manuel Hespanha, talvez tenha sido o responsável pelo [re]nascimento da aproximação entre dois campos disciplinares. Sua obra Às vésperas de Leviatan, (cuja primeira edição é de 1989), procurou compreender a organização do poder do Antigo Regime português, antes da publicação da teoria do contrato social de Hobbes, de 1651 (Hespanha, 1994). Formado pela Universidade de Coimbra - berço da disciplina no país - Hespanha é autor de extensa obra, referência obrigatória para os estudiosos do Direito e da História moderna. Seus livros e artigos tornaram-se um porto seguro para muitos dos historiadores que nos anos 2000 investigaram a natureza jurídica do sistema colonial. Além disso, grande parte da renovação da historiografia lusa se deve direta ou indiretamente à sua orientação (Cardim, 2011).

Não menos importante é, por um lado, a assumida influência do jurista espanhol Bartolomeu Clavero na obra do autor português. Os textos de Clavero se desdobraram também em estudos decisivos sobre a relação entre a História e Direito na Espanha, como por exemplo: Mayorasgo (Clavero, 1989). Por outro lado, é digna de registro a marcante ausência de leituras thompsonianas na obra de Hespanha, a começar por Panorama Histórico da Cultura Jurídica Européia, onde o autor, ao explicar o sociologismo marxista clássico e o marxismo dos anos 60 não faz nenhuma referência àquele autor, se contentando em destacar a contribuição de Gramsci, Althusser e Poulantzas (Hespanha, 1997).

Laura de Mello e Souza, por sua vez, é internacionalmente conhecida como a mais importante historiadora da época colonial do Brasil. Sua não menos extensa obra sempre esteve ancorada na obsessão por investigar o mundo colonial de carne e osso, dos pobres mineiros das Minas Gerais do século XVIII (Mello e Souza, 1983) aos administradores coloniais no mesmo período (Mello e Souza, 2006). Doutora pela Universidade de São Paulo, onde também atuou como docente e pesquisadora ao longo de décadas, foi orientanda de Fernando Novais, cuja inspiração nunca desapareceu de seus trabalhos.

Mello e Souza não é uma historiadora do Direito, mas talvez não seja gratuita 
sua preocupação em desnudar as importantes contribuições e incompletudes da historiografia clássica, como Caio Prado Junior, Raimundo Faoro e mesmo Sérgio Buarque de Holanda; todos com formação em direito, como era recorrente nos anos 30 a 60 . Por este viés, a autora pôde questionar em $O$ Sol e a Sombra muitas das afirmativas apressadas sobre a administração portuguesa do século XVIII. E também não à toa, explicitar sua crítica a algumas reflexões de Hespanha. Mas qual é querela?

É difícil saber qual foi a origem do embate. Fala-se muito de um evento em Parati, quando Laura de Mello e Souza teria explicitado suas críticas a João Fragoso, Maria Fernanda Bicalho e Maria de Fátima Gouvêa. O ponto central da crítica era - ao que parece - o conceito de Antigo Regime nos trópicos. Aqueles autores publicaram um livro com o mesmo título: O Antigo Regime nos trópicos (Fragoso, 2001). Ali, Hespanha escreveu um texto intitulado: "A concepção corporativa da sociedade e a historiografia da época moderna" (Hespanha, 2001). Neste texto, o autor português retomaria suas principais chaves de leitura para explicar as novas abordagens oriundas da aproximação da história e o direito. Como desdobramento, segundo o autor, sua obra permitiu um novo conceito de monarquia portuguesa (ao menos até meados do século XVIII) que se caracterizava por "um poder real [que] partilhava o espaço político com poderes de maior ou menor hierarquia"; pelo fato de que o "direito legislativo da Coroa era limitado e enquadrado na doutrina jurídica e pelos usos e práticas jurídicas locais", "os deveres políticos cediam perante os deveres morais (graça, piedade, misericórdia, gratidão) ou afetivos, decorrentes de laços de amizade, institucionalizados em redes de amigos e de clientes". Por último, "os oficiais régios gozavam de uma proteção muito alargada dos seus direitos e atribuições, podendo fazê-los valer mesmo em confronto com o rei e tendendo, por isso, a minar e expropriar o poder real" (Hespanha, 2001).

Para além dos méritos mais visíveis do texto, há a preocupação em destacar a multiplicidade de estatutos coloniais e a ausência de um corpo geral de direito, o que Ihe permitiu também afirmar a existência de uma justiça criola e a enorme autonomia de que gozavam os governadores, tanto para criar, como para dispensar direitos, assim como para exercer a graça.

Considerados como senhores das terras do Brasil que não estivessem em posse de nativos e colonos, a Coroa Portuguesa permitia que os donatários concedessem 
sesmarias. Os ouvidores dos donatários, por sua vez, "deviam inspecionar a legalidade da concessão e uso da terra, depois de concedida". A inspeção da legalidade era, segundo o autor, uma atribuição dos juízes demarcantes letrados propostos pela câmara. Além disso, as relações coloniais "veiculariam com eficiência os interesses dos poderosos locais, no julgamento de questões tão estratégicas como a interpretação de cartas de doação, a revogação de sesmarias, a instituição, sucessão ou desmembramento de propriedade vinculada (morgados e capelas) (Hespanha).

Os argumentos de Hespanha - ainda que coerentes - são, querendo ou não baseados nas normas legais que utilizou para elaborar suas conclusões. No direito vivido, porém, os documentos relativizam muitas das ilações do autor. Na prática, foram raríssimas as sesmarias devolvidas ao rei, a institucionalização do morgadio passava muitas vezes a largo dos interesses das câmaras, a pretensa capacidade dos juízes demarcantes de inspecionar a legalidade da ocupação já havia sido posta a nu pelos próprios governadores, como demonstrei em Direito à Terra no Brasil: a gestação do conflito. (Motta, 2009). Ademais, uma análise mais cuidadosa sobre o processo de concessão de sesmarias, como a realizada por Francisco Eduardo Pinto, nos mostra uma realidade mais imperscrutável do que um jogo restrito ao âmbito da relação entre governança e direito (Pinto, 2014). O projeto coordenado por Carmen Alveal sobre as concessões de sesmarias no país também nos ajuda a afirmar que há um denominador comum - a lei portuguesa de 1375 - mas ela é operada de forma diversa ao longo do tempo e em distintas capitanias. (PLATAFORMA S.I.L.B.). Se, como afirma Thompson, “na interface da lei com a prática agrária, encontramos o costume” (Thompson,1998), é impreterível admitir que a lei de 1375 era um substrato para leituras muitos diversas das que estavam registradas naquele ano. Em outras palavras, os contextos históricos eram muito distintos, os lugares eram outros e as leituras sobre a lei eram também variáveis. Entende-se assim, como aquela norma geral foi utilizada para conceder terras aos índios, para ceder terras às famílias pobres; "contrariando" - portanto o espírito da lei e das intenções primeiras da Coroa, quando de sua promulgação (Motta, 2009) (Alveal 2015a, 2015b).

Mas quais seriam as críticas mais centrais de Laura de Mello e Souza à posição de Hespanha sobre o direito na colônia, a partir de sua análise sobre o seu gerenciamento? Publicado em 2009, O Sol e a Sombra visou discutir - como já afirmei - a admi- 
nistração colonial que esteve marcada "por interesses metropolitanos que se combinavam aos regionais e acabavam produzindo alternativas peculiares". Neste sentido, não esteve exclusivamente preocupada com a noção de um direito strictu sensu, mas sim, como "as normas e determinações emanadas do centro do poder que [se] recriavam na prática cotidiana" (Mello e Souza,2009). Influenciada por Thompson, considerou também que a história é "a disciplina do contexto" (Thompson,1981).

Ao revisitar a produção clássica sobre a administração, em particular o emblemático livro do weberiano Raimundo Faoro e sua análise sobre o patriarcalismo brasileiro (Faoro, 1975) e a obra do marxista Caio Prado Junior (Prado Jr, 1973) e dialogar com a significativa produção estrangeira sobre a América portuguesa, Mello e Souza superou a percepção recorrente sobre a administração colonial, reduzida à condição de caótica e irracional. Por conseguinte, os autores estrangeiros, libertos de nosso passado colonial, foram hábeis em desnudar os elementos positivos da administração portuguesa, presentes nos trabalhos de Boxer, assim como eficazes em compreender as lógicas singulares do sistema administrativo do Império, como se verificam nos estudos John Russell-Wood e Francisco Bethencourt.

São a partir daqueles autores que Mello e Souza assume sua crítica à análise sobre o direito colonial de Hespanha. Em primeiro lugar, a autora assevera que é inquestionável sua contribuição para entender o Estado português e a administração do Império. O autor português, porém, desconsidera exatamente o enquadramento de suas reflexões mais gerais. Ao seguir as pistas inauguradas por Nuno Monteiro, Souza também afirma que "a análise de Hespanha se restringiria ao século XVII e pouco nos ajuda a refletir sobre administração e direito no século seguinte" (Mello e Souza, 2009).

Mello e Souza tem também razão ao questionar a ênfase dada ao próprio conceito de Antigo Regime, presente na obra organizada pelos colegas. Parece-me claro que as reflexões de Hespanha e seus desdobramentos na produção dos organizadores culminaram na importação de um conceito caro à França e à Europa, na tentativa de replicar aqui algumas chaves de leitura que só são possíveis no contexto europeu, em especial a singular indistinção entre o público e o privado e as "especificidades de uma ordenação estamental e corporativa". Além disso, se a ausência do Rei se desdobrava no reforço da imagem real, como bem observou Rodrigo Bentes, isso signifi- 
cava também que era possível acionar o seu nome, principalmente em momentos onde as querelas tinham que ser interpretadas a partir de normas legais disseminadas pela Coroa. A rigor, como bem alertara Toqueville, o Antigo Regime também havia se constituído a partir de uma "norma rígida" e "uma prática flácida", o que implica que é preciso desconfiar da aplicabilidade das leis. E no caso em questão, na colônia, "as contradições são mais exacerbadas, a convergência ou coincidência de práticas e interesses é não raro antes forma do que conteúdo" (Mello e Souza, 2009).

De todo modo, se há ou não um direito colonial, é fato que os historiadores brasileiros tenderam a valorizá-lo e ignoraram que as interpretações sobre as normas nem sempre são seguidas, são ignoradas em muitas ocasiões e são, ainda, aplicadas em diversas conjunturas, por distintas leituras da lei. Isso tudo, numa colônia de dimensão continental.

Como não se lembrar dos esforços da Coroa em impedir a constituição de grandes potentados rurais, que ocupavam terras ad infinitum, sem nenhum documento emitido pelo Poder? Mas não eram eles mesmos que sustentavam o Império? Em 7 de setembro de 1725, a Coroa expressou sua preocupação em relação à existência de vários domínios na América Portuguesa, em mãos de poucas famílias (Motta, 2011). 0 que aconteceu? Nada, ou se quiserem, muito pouco. O direito de concessão de sesmarias, limitado em dispositivos reais anteriores eram ineficazes para controlar a expansão rumo às fronteiras pretensamente abertas. De qualquer forma, era crível que muitos dos potentados e pequenos lavradores passassem a pedir algum documento que afiançasse a legalidade de sua ocupação. Nestes contextos, as normas legais podiam se apresentar como uma saída para o conflito, como discuti em O Direito à Terra no Brasil.

Naquele livro, eu argumentei que a noção de que a história moderna era fundada no direito, não deveria implicar fazer uma tábula rasa de conjunturas tão diversas. Hespanha havia argumentado que "muito mais do que a actual, a sociedade moderna era [...] fundada no direito. No sentido de que o direito e a justiça (e não a oportunidade, a competência técnica, o projecto político) constituíam a legitimação fundamental do Poder e a norma exclusiva do 'bom governo'. Segundo o autor, a sociedade do Antigo Regime "pese, embora, a ênfase sobre a harmonia e organicidade nas representações que de si produzia - conhecia uma profunda e endêmica conflitualida- 
de". Logo, os motins em Portugal seriam assim o resultado da crise de abastecimento e o aumento dos impostos. "Os grupos resistentes dispunham, na sociedade do Antigo Regime, de um instrumento particularmente eficaz - o direito". Ainda segundo Hespanha, meio de veicular os conflitos sociais, "o direito facultava outra eficaz estratégia de resistência - a da chicana burocrática" (Hespanha, 1998). Em contraponto, argumentei que as reflexões do autor português seriam insuficientes para indicar e dar a conhecer as percepções de direitos e justiça dos pobres. Por conseguinte, tanto no caso português quando em sua então principal colônia, seria preciso "historicizar melhor o papel do direito no Antigo Regime e evitar comparações entre os séculos XVI, XVII e XVIII" (Motta, 2009).

Em 2009, em uma nova coletânea organizada por Laura de Mello e Souza, Júnia Furtado e Maria Fernanda Bicalho, retomam-se as discussões sobre o Império português (Mello e Souza, 2009). Nesta obra, Mello e Souza resume suas reflexões apresentadas em $O$ Sol e a Sombra, destacando mais uma vez suas críticas à dimensão do direito de Hespanha e o uso equivocado do conceito de Antigo Regime. No mesmo livro, num texto intitulado “Por que é que foi 'portuguesa' a expansão portuguesa ou 0 revisionismo nos trópicos", Hespanha recupera algumas de suas anteriores reflexões, mas parece mais cuidadoso ao afirmar que havia uma linguagem cosmopolita de referência e se pergunta: "ao desenhar com tanta flexibilidade a arquitetura política do império colonial português, desprovido de centro e reduzido a uma meada confusa de laços de poder, a dúvida que fica é sobre se não estamos a desconhecer em demasia que todo o conjunto de espaços e de gentes tinha uma hierarquia clara, cuja cabeça era o rei de Portugal; que no seu seio se teciam relações assimétricas de poder; que era um lugar de domínio, de exploração e de cativeiro" (Hespanha, 2009). Em outras palavras, neste texto o autor português parece mais incomodado com os exageros produzidos pela excessiva noção da autonomia das colônias.

Sua resposta às críticas de Mello e Souza sairia de fato num artigo, publicado em 2007. Neste texto, Hespanha desnuda o que se chamava direito comum, muitas vezes não compreendido pelos historiadores. A seu ver, "uma das características do direito comum era "a sua enorme flexibilidade, traduzida no facto de o direito local se impor ao direito geral, e de, na prática, as particularidades de cada caso - e não as regras abstractas - decidirem a solução jurídica. Isso quer dizer que a centralidade do 
direito se traduzia, de facto, na centralidade dos poderes normativos locais, formais ou informais, dos usos das terras, das situações 'enraizadas' (iura radicata), na atenção às particularidades do caso; e, em resumo, na decisão das questões segundo as sensibilidades jurídicas locais, por muito longe que andassem daquilo que estava estabelecido nas leis formais do reino. O intento da detalhada citação era o de demonstrar que Laura de Mello e Souza havia, na verdade, confundido o direito com a lei. Neste artigo, Hespanha destaca a importância dos estudos de Cardim, a partir da noção de economia moral de Thompson (Hespanha 2007).

Hespanha é enfático ao reconstruir sua trajetória de aproximação com a história brasileira para reafirmar seu principal argumento: o pluralismo jurídico-político, na metrópole, mas também na colônia. $\mathrm{O}$ autor assevera ainda de que - ao contrário da afirmação de Mello e Souza - ele já teria coletado evidências suficientes para reconhecer as especificidades dos diferentes contextos imperiais. Como desdobramento, aquelas evidências reforçavam o seu modelo analítico, pois uma característica sistêmica do sistema político corporativo é o de exatamente "incorporar os localismos e reverberar as diferenças" Por isso, seria possível utilizar-se do conceito de Antigo Regime para a colônia.

Para além dos intentos pessoais de críticas que se confundem, é razoável pensar que ambos os autores são concordes em afirmar a pluralidade das decisões e a autonomia relativa dos vários cantões da colônia. Mas é impossível desconhecer o exagero de Hespanha em comparar a experiência camponesa da Europa com os cativos no Brasil. De fato, a experiência escravocrata marcou e demarcou uma diferença notável entre a Metrópole (e seu Antigo Regime) e a colônia. Não é suficiente afirmar que havia cativos na antiguidade. O tráfico de cativos tornar-se-ia um complexo processo de comercialização de corpos. Isso não era um mero detalhe. As leis estavam ali presentes para assegurar, sobretudo, o valor da mercadoria, o direito do "dono da coisa". Um camponês português poderia acionar as leis em defesa de seus pretensos direitos. Um cativo precisaria construir uma rede ainda mais complexa de solidariedade para demandar algo na justiça. Conseguir limitar o número de chibatadas, como outrora defendera Silvia Lara, não é a mesma coisa de assegurar um pedaço de terra de um pobre camponês luso. (Lara, 1988) 


\section{Direito, escravos e Antigo Regime.}

A dificuldade de operar com o conceito de Antigo Regime do outro lado do Atlântico tem na questão do escravo um ponto fundamental de discórdia. Os escravos não tinham direitos, era preciso criá-los no contexto colonial. O que Silvia Lara havia destacado ainda nos anos oitenta, era de que enquanto sujeitos históricos, os cativos poderiam ou tentavam alcançar algumas vantagens, num contexto em que a violência física era a regra, mas também passível de regras (Lara, 1988).

Assim, é razoável afiançar que ao contrário do que argumentara Hespanha não é possível falar de um direito colonial brasileiro - "com a importância política e institucional que isto tem" (Hespanha, 2006), sem considerar a fragilidade do sistema jurídico do Antigo Regime na colônia, até porque não há um antigo regime, atravessado por mercadorias negras. Se "os espaços jurídicos de abertura ou indeterminação é assistente na própria estrutura do direito comum" (Hespanha, 2006), os escravos estavam criando o seu mundo, adaptando normas de outrem, mas é difícil imaginar que teriam sido capazes de reafirmar singulares costumes nos espaços da lei.

É preciso ainda ressaltar que o direito comum é um vocabulário sutil e às vezes complexo de usos, reivindicações de propriedade, hierarquia e acesso preferencial a recursos (...) e "deve ser investigado em cada localidade e não pode ser jamais tomado como 'típico'"' (Thompson, 1998). Assim, há uma pluralidade de decisões, ancoradas num direito multifacetado. Por conseguinte, se o direito comum é o resultado de aplicação de normas e regras que não estão escritas, mas legitimadas pelo costume ou pela jurisprudência, cada querela inaugura um novo embate. Em cada cantão, o vocabulário ganha uma ossatura, às vezes bem diversa do que esperamos. Os direitos comuns são sempre específicos e locais. Se no domínio do direito, a lei é um preceito ditado por uma autoridade competente, é preciso reconhecer que sua aplicabilidade é sempre bem diversa da hipotética intenção inicial.

Talvez seja possível destacar que as reflexões de Hespanha e Mello e Souza e seus embates convergem para um denominador comum que, a meu ver, reduz o "incêndio inventado" da querela. De todo modo, eu compartilho da noção da impropriedade de se utilizar o conceito de Antigo Regime para a colônia.

Os estudiosos da Revolução Francesa certamente ficam surpresos com a vul- 
garização do conceito e sua hipotética aplicabilidade para as experiências coloniais. Nem mesmo Fraçois Furet, que tanto se esforçou por condenar a legitimidade daquela investida, ousaria estender o termo para além-mar, em sociedades escravocratas (Furet, 1978). Menos provável seria esperar dos historiadores jacobinos um acorde acerca do alargamento conceitual proposto (Vovelle, 1993, 2001). É razoável supor que as sublevações dos cativos tenham alguma similitude com o Grande Medo de 1789, estudado em obra magistral por Lefebvre e publicado pela primeira vez em 1932, mas as diferenças do contexto histórico e os distintos sujeitos históricos são tão gritantes que nem vale a pena perder tempo (Lefebvre, 1979). Os camponeses franceses procuraram salvaguardar direitos coletivos que estavam sendo destruídos pelos proprietários da segunda metade do século XVIII. Os cativos na América portuguesa procuravam criar direitos, em uma sociedade em que eles eram, sobretudo, mercadorias. Há uma enorme literatura sobre a influência dos princípios franceses nas sublevações da colônia, em fins do século XVIII. Mas influenciar não significa transplantar sujeitos e contextos históricos.

Há elementos comuns nas reflexões daqueles historiadores, mas é razoável supor que talvez consigamos compreender melhor o Direito exercido na colônia se nos beneficiarmos de alguns dos mais interessantes insights do historiador marxista Thompson e de Pierre Bourdieu. Nas páginas finais deste texto, vamos explorar melhor as reflexões do primeiro e apresentar as ilações do sociólogo e filósofo francês.

\section{O Direito Colonial em outra direção: Thompson e Bourdieu}

O que o texto "Costumes, Lei e Direito Comum" tem a nos dizer? Para além do que já afirmei, Thompson reitera que o costume é sempre local e em certas circunstâncias tinha força de lei. O autor britânico considera ainda que se os costumes não são escritos, tampouco registrados em regulamentos, ele pertence à prática e à tradução oral. Por conseguinte, ele poderia tornar-se refém das interpretações de alguns, ao mesmo tempo em que era factível identificar os direitos costumeiros dos pobres e impedir o seu exercício (Thompson, 1998).

É claro que a plasticidade do costume e os esforços dos grupos em "maximizar vantagens", aproveitando - cada um - dos costumes do outro, revela-nos a dificuldade 
de desnudar as intenções dos grupos em processos judiciais. Thompson está preocupado em esclarecer como foi possível criar barreiras legais que destruíram práticas agrícolas imemoriais, sustentáculos da economia camponesa da Inglaterra do século XVIII. Ao mesmo tempo nos mostra como os camponeses escolhiam - no arsenal de práticas costumeiras - aquelas que lhes serviriam para manter-se nas áreas pertencentes ao coletivo. Por esta razão, o costume é também o lugar do conflito de classe.

Em outras palavras, o arsenal de costumes tornou-se uma oportunidade para legitimar alguns e rejeitar outros. Assim, a noção que se consagrou sobre o direito consuetudinário implicou em reconhecer alguns costumes que fossem considerados razoáveis, respeitados e "sem prejuízo ao rei". A razoabilidade de um costume ou não se tornava assim a janela de constrangimento dos direitos dos pobres, já que eram os juízes que decidiriam o que era consequente. Se os costumes, porém, são fluidos, eles deveriam alcançar um grau de precisão absoluta em dois momentos: no julgamento do tribunal e no processo de cercamento dos campos. Mas isso nada tem de mecânico, "pois a lógica da racionalidade capitalista foi adiada por direitos de posse por aforamentos por costume profundamente arraigados" (Thompson, 1998). No entanto, a partir das dúvidas suscitadas pela admissibilidade dos costumes, era possível consagrar a propriedade exclusiva, impeditiva de experiências comunais. O conceito de propriedade se firmava então aos poucos, a terra consagrava-se como mercadoria e as reivindicações comunais se perdiam na poeira do tempo.

Na principal colônia portuguesa, os cativos eram mais valiosos do que a terra e eram principalmente eles - e não os pobres sem terra - que davam valor aos produtos por eles cultivados. A propriedade da terra era assegurada por alguns poucos, a despeito de uma enorme extensão territorial a ser "conquistada". 'A mercantilização da terra e do trabalho na paisagem americana ditada pela lógica do capital envolveu, por conseguinte, a expansão contínua das fronteiras da mercadoria", com base no trabalho escravo. (Marquese, 2013)

É difícil assegurar uma influência direta de Bourdieu no texto produzido por Thompson. Em suas notas, ele apenas cita Outline of a theory of practice, publicado em Cambridge, em 1977. Nesta nota, ele revela que havia usado o conceito de habitus de forma restrita. Mas em que sentido a obra de Bourdieu caminha lado a lado com as propostas renovadas de Thompson naquele texto de 1991? 
O filósofo e sociólogo francês, de origem camponesa como Lefebvre, teve uma trajetória acadêmica de enorme sucesso, a despeito de sua incessante e pertinente crítica à academia. "O que defendo', costumava dizer, 'é a possibilidade e a necessidade do intelectual crítico" (Weisseheimer, 2002). Em uma entrevista concedida a Luciano Trigo, alfinetou: "Os intelectuais de esquerda perderam suas ilusões relativas à ideia da revolução, por exemplo. Hoje é mais difícil lutar contra o poder porque ele se exerce de forma muito mais sutil. Mas é preciso reconhecer que existiam muitos intelectuais que eram falsamente engajados, homens que só com o tempo mostraram sua verdadeira face" (Trigo, s/d).

Seu primeiro trabalho esteve relacionado à comunidade de Calimba, na Argélia, onde prestou serviço militar. Ali desenvolveu uma reflexão original sobre as transformações agrícolas da região e refletiu sobre os "arranjos" familiares que faziam do casamento uma forma de sobrevivência no sistema de relações sociais e econômicas. Ainda na Argélia, iniciou a elaboração do conceito que nortearia toda a sua obra: habitus.

Autor de dezenas de estudos, Bourdieu tem um artigo marcante sobre o Direito, publicado em um dos seus livros: O Poder Simbólico, preparado para o público de língua portuguesa, em 1989 (Bourdieu, 1989).

Neste texto, com um pequeno número de páginas, o sociólogo francês desnuda "a força do direito", para escapar das visões simplórias: aquela que interpreta o campo independentemente das pressões sociais e a que, ao inverso, submete o direito como um reflexo direto das relações de forças existentes. Além disso, Bourdieu é atento aos limites da argumentação de Thompson que ao romper com o economicismo, não teria conseguido dar conta da especificidade do direito. É razoável supor, no entanto, que Bourdieu estivesse se referindo aos Senhores e Caçadores, e não ao texto presente em Costumes em Comum, publicado anos depois, com certa influência da perspectiva de Bourdieu.

Mas quais são as contribuições do autor? Em primeiro lugar, o sociólogo destaca que o campo jurídico é uma arena de disputa "pelo monopólio do direito de dizer o direito"; os que são "investidos de competência técnica e social para interpretar determinado corpus que consagram uma visão legítima ou justa do mundo social". Em outras palavras, o corpus jurídico expressa uma correlação de forças que pode, inclusi- 
ve, sancionar "as conquistas dos dominados convertidas deste modo em saber adquirido e reconhecido" (Bourdieu, 1989).

Mas a hierarquia da instituição jurídica não está restrita ao escopo judicial, mas também nas interpretações das normas, que se fragmentam em dois efeitos: “1. A neutralização, uma tentativa de marcar a impessoalidade do discurso através de construções na voz passiva; 2. A universalização, assentada em normas ou valores generalistas ou transobjetivos, com a quase inexistência de valores individuais". Além disso, os juízes possuem condições de explorar "a polissemia e a anfibologia das formas jurídicas para recorrer à restrictio (processo para não aplicar uma lei quando deveria ser aplicada) ou à extensio (processo de aplicação de uma lei "ao pé da letra", mesmo quando não necessária" (Bourdieu, 1989).

Há que se destacar ainda que os espaços e as linguagens jurídicas são restritos aos agentes que exercem o monopólio de dizer o direito. Por conseguinte, a despeito de uma imagem marcada pela neutralidade nas decisões e uma competência estritamente jurídica, "a referência a um corpus de precedentes reconhecidos, que funcionam como um espaço de possíveis em cujo interior a solução pode ser procurada, é o que fundamenta racionalmente uma decisão que pode inspirar-se, na realidade, em princípios diversos" (Bourdieu, 1989). Assim, ao contrário do que se imagina, a tradição jurídica incorpora várias decisões, muitas discordantes. De todo modo, são raras as decisões que prejudicam os dominantes, já que há uma vinculação estreita entre quem julga e os detentores do poder simbólico, político e econômico. Nessa estrutura de jogo, a ordem simbólica e o poder estão protegidos pelo campo jurídico que se apresenta como neutro.

\section{Para terminar, recomeçando....}

Talvez um dos maiores desafios aos historiadores provenha de sua crença no Direito e de um olhar um pouco ingênuo de percebê-lo como o lugar de nossa redenção enquanto humanos. Se ele é visto como o ordenamento normativo que rege a sociedade, é comum acreditar que acioná-lo implica ver reconhecido um direito que the foi negado. Por conseguinte, os investigadores quase sempre sublimam que o Direito é a expressão de jogo social, e não necessariamente culmina em um reparo, em uma 
justiça tão aguardados. Por isso, é muito importante dar a conhecer a marcante contribuição de Hespanha para as análises sobre a relação entre História e Direito.

O equívoco de muitos historiadores é o resultado de um desconhecimento de algo banal: há uma inegável ligação entre o Direito e o Estado. Desde Hobbes já se sabe que aquele amálgama converge para o processo de "estatização do Direito e de jurisdicialização do Estado" (Bobbio, 1991). Por este viés, tanto Hobbes, como Locke e mesmo Marx expressaram esta vinculação que tem em Marx a assertiva de que o Estado e o Direito são pertencentes à superestrutura. De todo modo, o Direito é bem mais do que um conjunto de regras que orientam a sociedade e impostas pelo Estado. Ele é também bem mais complexo do que uma ciência ou disciplina que garante a justiça dos povos.

Isso não significa afirmar que o interesse do Estado e da classe que o sustenta - os dominantes - sejam sempre assegurados pela operacionalização do Direito. Como afiança Hespanha, o Direito "normalmente, serve os mais poderosos, os que têm capacidade de influenciar, de subordinar, de sustentar com um litígio durantes anos em tribunal ou, pura e simplesmente, de se estribarem no parecer de um letrado por sua conta para desobedecerem ao direito estabelecido" (Hespanha, s/d).

Em suma, nas leituras possíveis das leis, é preciso separá-la de sua aplicabilidade em contextos e espaços diversos. Também é necessário recriar o jogo da querela, quem são os demandantes, quais são os lugares de atuação. Não é possível esquecer ainda o que está por detrás do cenário: como se colocam as testemunhas, quem são os parceiros e desafetos dos autores e réus. É fundamental ainda reconstruir o campo jurídico, juízes, oficiais do direito tem muito a nos dizer sobre o conflito. Mas é preciso ainda mais: desconfiar das leis e dos argumentos que a sustentam. A retórica jurídica não é feita necessariamente para esclarecer; pode ser pensada para confundir.

Por último e de forma menos acadêmica, talvez seja importante não esquecer de que a incerteza do Direito se revela também na expressão popular: "de cabeça de juiz e bunda de neném, ninguém sabe o que vem".

\section{Referências}

ALVEAL, Carmen. M. O.; BARBOSA, K. B. C. . 2015. A legitimidade da graça: os impactos 
da tentativa de reforço da política sesmarial sobre as terras da Casa da Torre na capitania da Paraíba (século XVIII). Topoi (Online): revista de historia, 16:78-100.

ALVEAL, Carmen M. O. 2015. Transformações na legislação sesmarial, processos de demarcação e manutenção de privilégios nas terras das Capitanias do Norte do Estado do Brasil. Estudos Históricos (Rio de Janeiro), 28:247-263.

ANDERSON, Perry. 2007. As idéias e a ação política na mudança histórica. In: BORON, Atilio A.; AMADEO, Javier; GONZALEZ, Sabrina, A teoria marxista hoje: problemas $e$ perspectivas. São Paulo, Expressão Popular.

BOBBIO, Norberto et al. 1991. Dicionário de Política. Brasilia, Editora UNB, volume 1, p. 349.

BOURDIEU, Pierre e Sayad. 1964. Le déracinement, la crise de l'agricultue traditionelle em Algérie. Paris, Ed de Minuit, pp. 212-231.

BOURDIEU, Pierre. 1989. O Poder Simbólico. Lisboa, Difel; Rio de Janeiro, Bertrand Brasil.

CARDIM, Pedro. 2011. "Entrevista a António Manuel Hespanha por Pedro Cardim". Análise Social, 46(200):430-445.

CLAVERO, Bartolomé. 1989. Mayorazgo. Madrid, Siglo XXI.

FAORO, Raimundo. 1975. Os donos do poder. Formação do patronato político brasileiro. 2a edição, Porto Alegre, Globo/EDUSP.

FURET, François. 1978. Penser la Révolution française. Gallimard, Paris.

HESPANHA, António Manuel. 2009. Por que é que foi 'portuguesa' a expansão portuguesa? Ou O revisionismo nos trópicos. In: MELLO E SOUZA, Laura de; FURTADO, Júnia e BICALHO; Maria Fernanda, O governo dos povos. São Paulo, Alameda, p. 61. . 2006. Direito Comum e Direito Colonial. In Panóptica, ano 1, (3):95. . 2001. A concepção corporativa da sociedade e a historiografia moderna. In: FRAGOSO, João; BICALHO, Maria Fernanda; GOUVÊA, Maria de Fátima, O Antigo Regime nos trópicos: a dinâmica imperial portuguesa (séculos XVI-XVIII). Rio de Janeiro, Civilização Brasileira, pp.163-181.

1998. A resistência aos poderes. In: MATTOSO, José (dir.), História de Portugal. Vol. 4: O Antigo Regime (coord. de António Manuel Hespanha). Lisboa, pp. 393395.

1997. Panorama Histórico da Cultura Jurídica Europeia. Portugal, Europa- 
América.

1994. Às vésperas do Leviathan: Instituições e poder político - Portugal - século XVII. Coimbra, Almedina.

LARA, Silvia. 1988. Campos da Violência: escravos e senhores na capitania do Rio de Janeiro, 1750-1808. Rio de Janeiro, Paz e Terra, p. 345.

LEFEBVRE, Georges. 1979. O grande medo de 1789. Rio de Janeiro, Campus.

PLATAFORMA S.I.L.B. Disponível em: <http://www.silb.cchla.ufrn.br/busca>. Acesso em: 25/01/2018.

PRADO Jr, Caio. 1973. Formação do Brasil Contemporâneo. 13a edição, São Paulo, Brasiliense.

MELLO E SOUZA, Laura de. 2006. O Sol e a Sombra: política e administração na América portuguesa do século XVIII. 1. ed., São Paulo, Companhia das Letras.

1983. Desclassificados do ouro: a pobreza mineira no século XVIII. 1. Ed, Rio de Janeiro, Graal.

MELLO E SOUZA, Laura de; FURTADO, Júnia; BICALHO, Maria Fernanda. 2009. O governo dos povos. São Paulo, Alameda.

MENDONÇA, Joseli Maria Nunes; LARA, Silvia Hunold (Org.). 2006. Direitos e justiças no Brasil: ensaios de História Social. Campinas, Editora da Unicamp.

MOTTA, Márcia. 2014. O Rural à la gauche. (Campesinato e Latifúndio nas interpretações da esquerda 1955/1996). Niterói, EDUFF.

. 2011. Minha Casa, minha honra: morgadios e conflito no Império Português.

In: MONTEIRO, Rodrigo et al., Raízes do Privilégio. Mobilidade social do mundo ibérico do Antigo Regime. Rio de Janeiro, Record, pp. 639-666.

2009. O direito à Terra no Brasil. A gestação do conflito (1795-1824). São Pau-

lo, Alameda.

MUNHOZ, Sidnei. 1997. Fragmentos de um Possível Diálogo com Edward Palmer Thompson e com Alguns de seus Críticos. Revista História Regional. 2(2) - Inverno.

PINTO, Francisco Eduardo. 2014. A Hidra de Sete Bocas. Sesmeiros e Posseiros em conflito no povoamento das Minas Gerais. (1750-1822). Juiz de Fora, Editora UFJF.

SILVA, Sergio. 2001. Thompson, Marx, os marxistas e os outros. In: THOMPSON E. P, As peculiaridades dos ingleses e outros artigos. Campinas, Editora da Unicamp, pp. 60-61. THOMPSON Edward. 1987a. A formação da classe operária. Rio de Janeiro, Paz e Terra, 
3 volumes.

. 1987b. Senhores \& Caçadores. Rio de Janeiro, Paz e Terra, pp. 338-355. . 1981. A Miséria da Teoria ou um Planetário de Erros. Rio de Janeiro, Zahar.

TRIGO, Luciano. (s/d). Entrevista com Pierre Bourdieu. Disponível em: <http://labs.icb.ufmg.br/lpf/Trigo,Entrevista-com-Pierre-Bourdieu.html>. Acesso em 25/01/2018.

VOVELLE, Michel. 1993. Combats pour la Révolution française. Paris, La Découverte. . 1993. Les Républiques scurs sous les regards de la grande nation. Paris, L'Harmattan.

WEISSHEIMER Marco. 2002. O legado crítico de Pierre Bourdieu. Revista Espaço Acadêmico, Ano I, (10).

Artigo recebido em 30 de outubro de 2017 e aprovado em 10 de janeiro de 2018. 